I

$A$ voZ 



\title{
Escuta e responsabilidade na relação com o outro em tradução
}

\author{
Mauricio Mendonça Cardozo \\ UFPR/CNPq
}

\begin{abstract}
Resumo
Muito há que se diga sobre o que deve uma tradução. E, tradicionalmente, tais deveres da tradução fundam-se na ideia de um dizer de novo, de um dizer pelo outro, de um dizer que faz às vezes de outro dizer. Impõe-se, a partir daí, uma noção de responsabilidade organizada centralmente em torno do dito do outro. Todavia, o estado da arte do pensamento contemporâneo não nos permite reduzir o outro apenas à esfera do dito, na medida em que não se pode ignorar a irredutibilidade de seus silêncios constitutivos. Nesse sentido, como pensar, hoje, a responsabilidade implicada na dimensão prática e ética dos fazeres e deveres que fundam o estatuto ontológico da tradução? Tomando por base uma leitura da noção lévinassiana de responsabilidade para o outro e de reverberações em especial na obra de Paul Celan, Jacques Derrida e Jean-Luc Nancy, este trabalho se propõe a apontar algumas implicações da noção lévinassiana de responsabilidade para a leitura e para a crítica de tradução.
\end{abstract}

Palavras-chave: tradução e relação; responsabilidade para o outro; descontinuidade; escuta; poesia e tradução.

\begin{abstract}
Much is said about what a translation should do. Traditionally, such duties of translation are grounded on the assumption that translating is saying again, saying something that takes the place of another saying. From there arises a sense of responsibility that is strongly linked to the saying of the other, to the idea of another subscribed by his saying. However, the state of art of contemporary thought does not allow us to reduce the other to the limits of his sayings, since one cannot ignore the other's irreducibility, the irreducibility of the silences beyond his sayings. In this sense, how tore think, now a days, the responsibility implied in the practical and in the ethical dimensions that ground the ontological status of the translation? On the basis of a reading of Levinas's notion of responsibility to the other and of other reverberations specially in the work of Paul Celan, Jacques Derrida and Jean-Luc Nancy, this paper aims at pointing out some implications of Levinas's notion of responsibility to the reading and to the criticism of translation.
\end{abstract}

Keywords: translation and relation; responsability to the other; discontinuity; listening; poetry and translation. 
1. GUIMARÃES ROSA, João. Grande Sertão: Veredas, 1986, p.505.

2. Do poema "WEISSGRAU", no livro Atemwende. CELAN, Paul. Die Gedichte, 2003a, p.177.
O que é que uma pessoa é, assim por detrás dos buracos dos ouvidos e dos olhos? João Guimarães Rosa ${ }^{1}$

Ein Ohr, abgetrennt, lauscht.

Ein Aug, in Streifen geschnitten, wird all dem gerecht. Paul Celan ${ }^{2}$

É comum à epígrafe a condição de fragmento, o acidente do recorte, o incidente de um corte que a delimita, de um corte que a aparta como parte, do corte que é redução e interrupção do outro, mas que é também abertura. Pois que, pela posição que ocupa e que a define -não somente acima, não somente no começo, mas, a um só tempo, como parte integrante e parte à parte de um novo texto-, é comum à epígrafe, a partir do corte que lhe dá sentido, abrir-se como condição de início desse outro texto e, nessa condição, ressignificar-se e ressignificá-lo.

Aqui, dois recortes de duas obras de duas línguas de dois nomes que assinam e se deixam assinar como Rosa e Celan. Nas relações em epígrafe, a frase de todo um romance, os versos do fim de um poema e mais: dois outros interrompidos, inscritos no corpo de outro texto, de um texto sobre o outro, sobre o corte e a tradução do outro, sobre a responsabilidade, sobre a escuta - como epígrafes da relação com o outro.

Falar de epígrafe, portanto, também por falar do outro.

\section{a questão do outro, o outro como questão}

O outro não é figura pouco freqüentada no campo de discussão da tradução. Há certa vertente de um pensamento moderno sobre a tradução - que não podemos deixar de fazer remontar ao pensamento de nomes como Rousseau, Hamann, Herder, ou a reflexões em sua esfera mais ou menos direta de influência, de nomes que vão de Goethe e Schleiermacher a Hölderlin -, para a qual o outro surge como uma figura de destacada importância.

Moderno - abreviando o inabreviável de tão ampla discussão - significa, também nesse contexto, um pensamento per- 
meável aos impactos da longa passagem de uma compreensão do homem como indivíduo para uma compreensão do homem como sujeito. Nesses termos, podemos dizer, assumindo aqui o ônus da simplificação, que o pensamento dito clássico sobre a tradução estaria mais voltado para as problemáticas do enquadramento (numa determinada ordem do discurso - a exemplo da produtividade das discussões em torno do ideal do bem traduzir) e do pertencimento (a determinada ordem na polis, ${ }^{3}$ na tradição - a exemplo da centralidade da imitatio e da aemulatio, como questão e como prática). Já o pensamento dito moderno sobre a tradução, sem descartar as questões discutidas desde a Antiguidade - não raro numa matriz retórica ou no horizonte de seus valores -, faria somar a estas a ideia de que, em minhas palavras, toda tradução articula uma relação com o outro e de que, ao fazer isso, toda tradução também constitui ocasião propícia para uma percepção tanto de si mesmo quanto da ordem relacional que se estabelece e se equaciona entre um eu e um outro na tradução.

É no sentido dessa percepção relacional que a tradução se colocaria a serviço da Bildung romântica, como podemos ler, por exemplo, a partir da clássica conferência de Schleiermacher ${ }^{4}$. Nesse texto, numa sequência de distinções entre várias formas e campos da prática tradutória, o filósofo, teólogo e tradutor alemão recorta exatamente a modalidade de tradução (de relação tradutória) que lhe parece a mais adequada aos propósitos pedagógicos e políticos da Bildung, ao mesmo tempo em que, num movimento duplo, identifica a ordem particular de relação que a tradição francesa de tradução equaciona entre o próprio e o outro e vislumbra um caminho diferente para os destinos da tradução em língua alemã - bem como para os destinos da língua alemã via tradução. Para Schleiermacher interessa especialmente um determinado modo de se traduzir, leia-se: um determinado modo de se articular uma relação com o outro, um modo de relação a partir do qual o outro não seja imediatamente reduzido ao próprio, um modo de relação a partir do qual o outro possa agir sobre nós na surpresa e no assombro de sua diferença, como força transformadora. É nesse sentido mais específico que o surgimento do outro e da relação com o outro como questão podem ser considerados traços fundadores do estatuto de modernidade no pensamento sobre a tradução.

No campo específico dos Estudos da Tradução, esse pensamento ganharia novo fôlego a partir das décadas de 80 e 90 do século XX, mais notoriamente na voz de teóricos contemporâneos da tradução como Antoine Berman e Lawrence Venuti, aquele em sua defesa de uma tradução anti-etnocêntrica ${ }^{5}$, este ao problematizar as consequências, para o tradutor e para o outro em tradução, de um modo dominantemente domesticador de traduzir no contexto anglo-americano ${ }^{6}$.
3. Rousseau dirá, por exemplo: "Un citoyen de Rome n'étoit ni Caïus, ni Lucius; c'étoit un Romain”. ROUSSEAU, Jean-Jacques. Emile ou De l'éducation, 1841, p.24.

4. SCHLEIERMACHER, Friedrich. Sobre os diferentes métodos de tradução, 2001, p. 26-87.

5. BERMAN, Antoine.

L'épreuve de l'étranger, 1984.

6. VENUTI, Lawrence. The translator's invisibility, 1995. 
7. Exceção seja feita ao trabalho $A$ singularidade na escrita tradutora, de Maria Paula Frota, publicado em 2000, que pode ser visto como um enfrentamento direto dessas questões no campo de interface da tradução e da psicanálise. Infelizmente, a incorporação dessa discussão como contraponto ou modalização de certa recepção dos trabalhos de Lawrence Venuti e Antoine Berman ainda se mostra bastante discreta.
Todavia, a despeito de o pensamento desses autores ser referência corrente na pesquisa contemporânea da área - amparando ou fundamentando reflexões que, ao problematizarem questões de ordem ética e política, partem em defesa do outro (do estrangeiro, do estranho) na tradução -, ainda são discretos $^{7}$ os esforços voltados para a discussão da questão suscitada pela citação de Guimarães Rosa em epígrafe: afinal, aquém e além de seus buracos, que outro é esse que defendemos?

Por ora, mais interessa a pergunta de inspiração roseana do que sua resposta, pois a pergunta pressupõe uma dúvida que coincide com a questão que, aqui, é central: esse outro - o outro de que tanto falamos, que defendemos por princípio ético, que traduzimos ou que deixamos escapar em nossas traduções -, não nos parece que possamos assumir que esse outro esteja dado, ainda que freqüentemente nos refiramos a ele como se estivesse. Não podemos tomar o outro como algo inequívoco, como plenamente totalizável na figura que dele fazemos, como perfeitamente apreensível nessa redução que faz valer o outro. O outro é mais do que o outro para nós, para mim, para você.

A dúvida implícita na pergunta do narrador roseano nos lembra de que não podemos simplesmente estender nossa certeza da factualidade da existência do outro como um outro que funda nossos mais diversos compromissos éticos - a uma certeza da possibilidade de percepção do outro em sua alteridade, na totalidade e na singularidade de sua alteridade factual. Em outras palavras: o fato de que o outro existe como um outro não garante nossa percepção dele como tal.

Como um valor de operação, o outro para mim - o outro em mim - circula como valor de outro numa economia da relação, mas isso não implica pressupor a paridade entre o outro e as percepções que dele se têm. A bem da verdade, tal pressuposto não tem lugar - ao menos desde Hume, ou Kant - em nenhuma vertente de pensamento que se assuma como moderna. O que há - talvez assim se possa precisar melhor o problema - é que, pelos mais variados motivos - sem descartar os de natureza operacional, que, no entanto, nunca se apresentam como meramente operacionais -, talvez nos façamos indiferentes, talvez deixemos muitas vezes de considerar essa diferença (entre o outro e nossa percepção do outro) como um dado conseqüentemente relevante em nossas discussões e, nisso, sigamos discutindo como se assumíssemos a possibilidade de desprezar essa diferença não desprezível - uma diferença cuja dimensão, assumindo-se a infinitude lévinassiana do outro, será sempre infinita.

O que é o outro? Eis uma pergunta que permanece em aberto e que, de certo modo, responde-se justamente por manter-se sempre em aberto, por manter-se como questão, ao 
menos na medida em que a esse não-fechamento da questão corresponda uma aceitação da condição de irredutibilidade do outro a uma forma particular de percepção.

O que é o outro para mim? Eis uma pergunta que começa a se responder à medida que nos damos conta de que sua resposta não é inequívoca, de que há inúmeras respostas para essa pergunta e de que, portanto, é preciso levar suas diferenças em consideração em nossas discussões que operam com valores do outro.

As evidências: há um outro, que não é simplesmente um outro eu; há um outro, cuja existência não se define exclusivamente à minha diferença - nenhum outro se esgota nos termos da relação com um determinado eu, como mero efeito de espelho; ${ }^{8}$ há um outro aquém e além de sua diferença em relação a mim, à revelia de meus buracos ou à parte o fato de eu ser alguém que tem ou não buracos.

A questão: como pensar o impacto dessas evidências num pensamento sobre a responsabilidade que se impõe na relação com o outro em tradução?

A questão se desdobra. Para discutir a questão da responsabilidade na relação com o outro, é preciso antes pensar a condição do outro nessa relação, pensar o outro em suas semelhanças e diferenças em relação a nós, mas também quanto àquilo que nele é diferença para além da relação conosco. É preciso pensar o outro em suas continuidades e descontinuidades, o que implica também pensar em que medida o corte e a interrupção podem ser entendidos como gestos constitutivos da percepção do outro em sua alteridade.

\section{o corte, o outro interrompido}

A propósito do corte, uma leitura do recorte: da epígrafe como parte apartada e como interrupção que ressignifica o texto em que se inscreve.

Os versos em epígrafe, do poeta Paul Celan, recortam a parte final de um poema publicado no primeiro dos seis ciclos de seu livro Atemwende 9 . Em sua ampla recepção, que também incluiria uma atenção para além do campo da crítica literária e dos estudos celaneanos ${ }^{10}$, as vias mais frequentes de leitura e tradução do neologismo Atemwende apontam claramente para o privilégio de sua acepção física, seja no sentido da alternância de um fluxo de ar, como, por exemplo, em mudança de ar, mudança de respiração, mudança de inspiração, virada de fôlego, giro de fôlego, ar-reverso, sopro, viragem ${ }^{11}$, seja no sentido
8. Não se trata aqui de desconsiderar a ação dessa lógica lacaniana sobre o eu, trata-se apenas de não limitar o outro à circunscrição especular dessa ação.

9. CELAN, Paul. Atemwende. In: Die Gedichte, 2003a, p.177. O livro foi publicado originalmente em 1967.

10. É especialmente a partir de poemas deste livro que se organizam os trabalhos Wer bin Ich und wer bist Du? (1986), de Hans-Georg Gadamer, e Schiboleth pour Paul Celan (1986) e Béliers - Le dialogue ininterrompu (2003), de Jacques Derrida.

11. Refiro-me aqui às vias de leitura e tradução de tradutores e críticos como Flávio Kothe, João Barrento, Maria João Cantinho, Claudia Cavalcanti, Guilherme Flores, Mariana Oliveira, Raquel Abi-Sâmara, Márcio Seligmann-Silva, Vera Lins, entre outros. A recepção em outras línguas como o inglês, o francês, o espanhol e o italiano parecem acompanhar essa mesma tendência. 
12. Jean-Pierre Lefebvre em: CELAN, Paul. Renverse du souffle, 2003b, p.128.

13. Vide, por exemplo, o verbete Athem, no Dicionário dos Irmãos Grimm: Deutsches Wörterbuch von Jacob und Wilhelm Grimm, obra de referência que mantém uma edição online em http:// woerterbuchnetz.de/DWB/.

14. Conforme lemos no verbete de Grimm, em Althochdeutsch (estágio da língua alemã anterior ao Mittelhochdeutsch da Alta Idade Média) haveria indícios de uma hesitação no uso de Athem (âtum) ou Geist para a tradução da noção de spiritus sanctus. da pausa de respiração, com ênfase no instante que se interpõe à mudança no fluxo de ar, a exemplo da leitura desenvolvida por Jean-Pierre Lefebvre ${ }^{12}$.

De fato, o termo Atem ${ }^{13}$, já a partir da Alta Idade Média, ocorre dominantemente nessa sua acepção mais sensível, física, com a ideia de respiração, sopro, hálito. No entanto, em estágios anteriores da língua alemã, que remontam a usos ainda mais antigos das línguas germânicas que constituíram sua matriz de formação, também convive com essa ocorrência dominante uma acepção abstrata de Atem, mais pontual e instável, ${ }^{14}$ que se relaciona semanticamente com noções que vão desde a capacidade humana da fala até as noções de alma e espírito. Assim, levados em consideração os rastros de seus usos ancestrais - um interesse e uma atenção que não eram nada estranhos a esse poeta tão afeito à pluralidade de nuances e aos usos desacostumados da palavra -, o termo Atem passa a circunscrever um campo semântico mais amplo, que vai da noção de sopro (de ar em movimento, respiração, fôlego), passa pela noção de fala e se estende até a noção de alma, de espírito.

Diante dessa complexa rede semântica, a noção de Atem se adensa para além de uma realidade física. A acepção como sopro ou respiração recorta metonimicamente sua dimensão dinâmica, mas também deixa mais à margem uma possibilidade de leitura que, explorando a amplitude de seu campo semântico, opte por dar ênfase à dimensão anímica desse ar em movimento (ou em alternância de movimento). Nessa via mais lateral de leitura, a ênfase passa a incidir sobre os ânimos e a anima que põem o ar em movimento, ou que ganham vida, são animados pelos movimentos desse ar, como sopro de vida. Atem ganha assim a densidade de um sopro que tem sentido e faz sentido, de um sopro que diz, de um sopro que significa: como uma palavra dita. E na condição de um sopro de palavra, Atem passa a ter a densidade de uma voz.

Para Celan, trata-se, porém, de uma Atem-Wende. Mudança, giro, virada, viragem, todos os caminhos mais frequentes de tradução e leitura do termo Wende inscrevem-se no campo semântico da mudança de determinada condição. E mesmo sem pensarmos ainda em suas diferentes topicalizações - como na ideia de repetição, implícita num termo como alternância, na ideia de passagem, implícita num termo como transição, ou na ideia de transformação, implícita num termo como modificação -, a noção de Wende, enquanto mudança, está fortemente ligada a uma ideia de interrupção, de corte e, portanto, de descontinuidade.

A voz é sopro, é ar em movimento, mas é também anima, signo de um outro. No campo das possibilidades de leitura, Atemwende se reescreve, assim, como interrupção de um sopro anímico, como um corte de voz, como descontinuidade do outro. 
Essas linhas de força, sintetizadas nas figuras do corte (da descontinuidade) e da voz (do outro), projetam-se menos como um esforço de solução do enigma celaneano,do que como uma forma de dar lugar ao que ainda somos capazes de evocar ${ }^{15}$ a partir da leitura de Atemwende como uma peça sensível de composição.

Atemwende dá título, nomeia um livro de poemas, mas é também o termo de que o poeta se serve para, numa passagem famosa e decisiva de seu Meridiano, ${ }^{16}$ reposicionar sua visão de poesia. Em tradução de Flávio Kothe, lê-se: "Poesia: isso pode significar uma mudança de respiração." ${ }^{17}$ Reformulada a partir de uma leitura menos mecânica da noção de Atemwende, poesia, para Celan, pode (tem a possibilidade, a ocasião de) significar um corte de voz, uma descontinuidade do outro.

Ora, essa reformulação reverbera fortemente em algumas das hipóteses (questões) que Celan levanta ainda nesse mesmo parágrafo de seu Meridiano. Repensando a partir de uma Atemwende o campo de possibilidades da poesia (do poético), o poeta propõe: "vielleicht gelingt es ihr [à poesia] hier, zwischen Fremd und Fremd zu unterscheiden" (grifo meu). ${ }^{18}$ Em outras palavras, como Atemwende, como um corte de voz, talvez a poesia consiga diferençar (unterscheiden: noção também fortemente marcada pela ideia de separação, de corte) o que, para Celan, parece se manifestar de modo indistinto: como uma aparente continuidade do estranho, do estrangeiro, do outro, ou mesmo do estranho em mim; uma continuidade de Fremd em Fremd - diferença apagada em sua manifestação como in-diferença.

E o poeta encerra esse movimento de seu pensamento com um novo desdobramento de hipótese, em que justamente o diferençar da indiferença entre Fremd e Fremd, surge como um gesto de liberação (frei werden), de libertação (frei setzen) da indistinção entre um eu e um outro. Na tradução de Kothe: "Talvez venha a ser aqui, com o eu - com o eu aqui e de tal forma libertado e estranhado -, talvez venha a ser aqui ainda libertado um Outro?" ${ }^{19} \mathrm{~A}$ poesia, reverberando os cortes e as descontinuidades de uma Atemwende, torna-se possibilidade (ocasião) de que um eu e um outro tenham lugar em suas diferenças. $\mathrm{O}$ eu, no corte da indistinção, na percepção da diferença, na atenção que o estranha (befremdet), na interrupção que o descontinua de uma aparente continuidade no outro, surge então como um eu liberto (freigesetzt) da condição de indiferença e, nisso, dá ocasião para que o outro também fique livre (wird freı) da condição que, doutro modo, não faria senão aprisioná-lo como um outro-eu. Na poesia como Atemwende, um eu não indiferente tem ocasião de dar lugar a um outro como um outro outro.
15. Sandra Stroparo, no artigo

"O caminho do silêncio:

Mallarmé e Blanchot", publicado em 2013, destaca, a partir de sua leitura de Mallarmé, a noção de evocar como uma forma de dizer o silêncio. Diferentemente do dizer, que, não raro, parece pressupor um compromisso de totalização no dito, o evocar, como uma outra forma de dizer - que aceitaria seus silêncios -, parece assumir como condição a impossibilidade dessa totalização.

16. CELAN, Paul. Der Meridian, 1999.

17. CELAN, Paul. O Meridiano, 2011, p.52.

18. Em português: quiçá calhe à poesia, aqui, discernir entre estranho e estranho.

19. Ibidem. 
É essa Atemwende, como descontinuidade, que reverbera no primeiro verso de Celan que epigrafa este texto:

Ein Ohr, abgetrennt, lauscht.

Lauschen é o verbo de uma escuta velada e com atenção, como no caso da observação atenta da noção de espreita, que, no entanto, parece implicar mais um campo do visual do que o campo auditivo. Trennen é o verbo da separação, enquanto abtrennen enfatiza a noção de separação de algo que antes se apresentava ligado. Mas não podemos fazer ouvidos moucos para o caso de $O h r$, em alemão, que cobre um campo semântico bastante amplo. Ohr é a orelha em que se penduram brincos (há em alemão um termo específico, Ohrmuschel, mas é mais restrito, técnico). Ohr é a parte do corpo que teria sido decepada por Van Gogh. Mas Ohr também é o ouvido, no sentido de todo o aparelho auditivo, interno e externo; e também no sentido de se dizer que somos todo ouvidos (ganz Ohr sein). O sentido da audição vale-se de um termo diferente (Gehör), mas Ohr é usado ainda na acepção da capacidade, da habilidade de ouvir (Hörkraft), também implícita na disposição, concentração e atenção da ideia de ser todo ouvidos.

De certo modo, estamos diante de um movimento semelhante ao da discussão de Atem. Diante do imperativo de sua tradução para o português, também no caso de Ohr temos de decidir entre uma acepção que evoca mais centralmente sua dimensão física (orelha) e uma acepção que evoca seu sentido, digamos, mais operativo (ouvido). Para fazer reverberar aqui uma Atemwende, o verso pode ser traduzido como:

Um ouvido, apartado, escuta.

A orelha se aparta de um corpo. O ouvido se aparta de um modo de ouvir.

Traduzido desse modo, o verso sugere uma determinada condição de escuta. Para ouvir o outro de outro modo, para escutar o outro em sua alteridade, é preciso romper a indistinção, interromper a condição de indiferença em que ouvimos o outro, mas sem de fato escutá-lo, sem de fato lhe dar ouvidos.

\section{l'étrange césure: interrupção e diálogo}

A interrupção como condição da relação com o outro (enquanto um outro) é também uma questão central para Jacques 
Derrida em Béliers - Le dialogue interrompu: entre deux infinis, le poème, originalmente uma conferência proferida em 2005, em Heidelberg, em memória de Hans-Georg Gadamer. Nesse texto, Derrida refere-se, inicialmente, à interrupção imposta pela morte do filósofo alemão, em 2002 - a uma interrupção que, entre amigos, sempre há de se impor a uma das partes: "un jour la mort devra nous séparer. Loi inflexible et fatale: de deux amis, l'un verra l'autre mourir'. ${ }^{20}$ Mas refere-se também à outra interrupção, datada de um primeiro encontro entre os filósofos em Paris, no ano de 1981, um encontro marcado, como dirá Derrida: por uma "étrange interruption, autre chose qu'un malentendu, une sorte d'interdit, l'inhibition d'un suspens". ${ }^{21}$ Trata-se da interrupçãode um diálogo que atravessava justamente questões de interpretação (de hermenêutica da obra de arte) e da interpretação (da leitura)de poemas de Celan, uma interrupção que será interpretada por outros filósofos como um mal entendido, como "un malentendu originaire", 22 mas que, para Derrida: "Loin de signifier l'échec du dialogue, telle interruption pouvait devenir la condition de la compréhension et de l'entente". ${ }^{23}$

Por ocasião desse primeiro encontro, Derrida havia preparado três perguntas para Gadamer. A terceira delas seria decisiva para o destino de seu diálogo:

Cette question marqua à la fois l'épreuve, sinon la confirmation du malentendu, l'interruption apparente du dialogue mais aussi le commencement d'un dialogue intérieur en chacun de nous, un dialogue virtuellement sans fin et quasiment continu. ${ }^{24}$

Em Béliers, Derrida retoma essa pergunta, então centrada na discussão da condição interpretativa do que Gadamer chama de Verstehen:

[...] on peut encore s'interroger sur cette condition axiomatique du discours interprétatif que le Professeur Gadamer appelle le Verstehen, le 'comprendre l'autre', le 'se comprendre l'un l'autre'. [...] on peut se demander si la condition du Verstehen, loin d'être le continuum du 'rapport', comme cela fut dit hier soir, n'est pas l'interruption du rapport, un certain rapport d'interruption, le suspens de toute médiation. ${ }^{25}$

Aqui, a descontinuidade e o corte celaneanos reverberam na questão da interrupção derridiana. Contra o pressuposto de que a relação com o outro seria marcada pelo signo da continuidade, Derrida se pergunta se não seria justamente o oposto, se não seria necessário quebrar esse continuum, descontinuá-lo para que uma compreensão do outro (enquanto outro) tivesse
20. DERRIDA, Jacques. Béliers Le dialogue ininterrompu, 2003, p.20.

21. Ibidem, p.10.

22. Ibidem, p.15.

23. Ibidem, p.21.

24. Ibidem, pp. 20-21.

25. Ibidem, pp. 21-22. 
26. Ibidem, p. 38. Aqui, a formulação de Derrida reverbera, talvez seja mesmo o caso de dizermos que parafraseia a ideia de Atemwende.

27. "S'il est un plaisir / c'est bien celui de faire l'amour / le corps entouré de ficelles / les yeux clos par des lames de rasoir" (grifo meu). PÉRET, Benjamin. Euvres complètes, 1969, p.167. lugar. A interrupção da relação reformula-se, assim, como uma étrange césure, como uma relação de interrupção, como uma relação sob o signo da descontinuidade, do corte - e por que não dizer, de uma Atemwende: um corte de voz que dá sentido ao outro como um outro, a um outro interrompido: "suspendue au soufle de l'autre parole et de la parole de l'autre”. ${ }^{26}$

\section{o corte, a cena, o corte em cena}

Tanto na Atemwende celaneana quanto na interrupção derridiana, trata-se, num só movimento, de colocar em causa o sentido do corte e o corte como gesto de sentido. Os dois versos finais do poema de Celan em epígrafe reforçam esse duplo sentido:

Ein Aug, in Streifen geschnitten, wird all dem gerecht.

Se podemos dizer que, noutra via de leitura, o verso anterior poderia evocar indiretamente uma cena ligada ao mundo das artes plásticas - o corte da orelha de Van Gogh -, nesses outros dois versos parece incontornável a evocação da antológica cena da navalha que corta o olho, sequência inicial do curta-metragem Um cão andaluz (1929), de Luis Buñuel. E essa cena, por sua vez, já parecia fazer reverberar um verso do poema Les odeurs de l'amour, ${ }^{27}$ do poeta francês surrealista Benjamin Péret, tão caro a Buñuel e a Dali (que também colaboraria na construção do roteiro desse filme).

Como se já não bastasse a força da cena como cena de um corte - em que o corte é tema: corte do olho, corte de um modo de ver, corte de um modo de se relacionar com o mundo e com a vida -, ao mesmo tempo a sequência representa um caso paradigmático de utilização do corte como recurso de construção fílmica, a exemplo do modo como se entrecortam o plano do homem que olha ao longe, o plano da lua e da nuvem em movimento e o plano da mulher cujo olho é cortado pela navalha. Se aos nossos olhos acostumados à produção filmográfica do século XXI, é possível que a sequência nos pareça quase didática, a impressão, por certo, terá sido muito diferente por parte dos expectadores do final da década de 20 do século passado, desacostumados ainda a uma sequência tão intensa de cortes e à não linearidade que ela impõe à narrativa.

À semelhança da cena de Buñuel, os versos de Celan não apenas tematizam o corte do olho em tiras (Ein Aug, in Streifen geschnitten), como também evocam a ideia do corte como 
gesto de construção da cena, como mise en scène desse olho em corte.

Streifen, para além do sentido como tiras, tem também uma acepção como filme (ainda que bem menos corrente). Em conjunto com o verbo schneiden, que aparece no poema na forma do particípio geschnitten, esse sintagma, para além de sua acepção mais direta de corte em tiras, evoca também a ideia de cortar em filme como fazer um filme, em que a referência à técnica específica do corte (e da montagem implícita) ganha o sentido mais geral de construção de uma narrativa fílmica. Um movimento semântico semelhante a este ocorre, em português, com a noção de rodar na expressão rodar um filme. Lido assim, esse mesmo verso evoca, a um só tempo, o olho cortado em tiras e a ideia de um olho cortado em filme: de um olho cortado, que, nos cortes constitutivos da cena, constrói-se, também, como o corte em cena.

O poema inteiro pode ser lido nessa perspectiva. Num primeiro plano, o olhar distante, na suspensão de um sentimento tão abrupto - a um só tempo íngreme e interrompido - quanto as escarpas escavadas pela ação do tempo (natureza) e do tempo (cronológico). Os sentimentos escarpados - que evocam falésias numa cena que se assuma praiana - restam apenas como o corte abrupto e como o gris alvo escavado - duas cores que ao mesmo tempo nem branco, nem cinza, um furta-cor alegórico no tempo das indecisões, das decisões, das cisões.

\section{GRISALVO \\ escavado de ab- \\ rupto sentimento.}

Corte. No segundo plano, ao invés da lua e a nuvem em movimento, a aveia do mar (Strandhafer) - essa planta pioneira que relva a areia da praia - ao mesmo tempo é varrida pelo vento (Landeinwärts, costa dentro das terras do eu) e sopra seus veios de areia (deixa seus rastros) sobre o baço embaralhado, sobre o ruço da miragem das lembranças de outrora.
Costa dentro, varrida
pelo vento a relva sopra
veios de areia sobre
o ruço das canções de fontana.

Corte. O plano do ouvido é um plano frontal, todo corte como condição da escuta. Vale lembrar que o curta-metragem de Buñuel é um filme originalmente mudo, em que o ouvido, portanto, é apartado do jogo dos sentidos - mas é também a partir dessa interrupção que se constrói uma nova forma de atenção. 
28. WEISSGRAU aus- /

geschachteten steilen /Gefühls.

//Landeinwärts, hierher- / verwehter Strandhafer bläst / Sandmuster über /den Rauch von Brunnengesängen. //Ein Ohr, abgetrennt, lauscht. //Ein Aug, in Streifen geschnitten, / wird all dem gerecht. (CELAN, Atemwende. In: Die Gedichte, 2003a, p.177)
Um ouvido, apartado, escuta.

Corte. O plano do olho em corte, que faz jus a tudo isso, que dá sentido aos planos todos, cortados em filme. Em português, a opção um olho, cortado em filme explicita algo que, no sintagma alemão, resiste à explicitação, é mais sutilmente evocado, é dito em seus silêncios. Mas o olho cortado é também o olho que se cega, de que se aparta a vista, o que evoca também o efeito de seu corte, seu sentido. E os acidentes da língua portuguesa nos oferecem um verbo homófono ao verbo cegar - segar, que significa seccionar, cortar em tiras. A opção por segar, é claro, marca o verso a sua maneira, mas também abre uma possibilidade de evocar aquelas nuances do sintagma alemão de um modo menos explícito: a do corte em tiras, como um segar, e a do corte como um gesto de sentido, por homofonia, como um cegar - o corte como construção dessa condição. Segar o olho para cegar um modo de olhar, provocar sua descontinuidade e, assim, abrir-se a outros sentidos.

\author{
GRISALVO \\ escavado de ab- \\ rupto sentimento.
}

Costa dentro, varrida

pelo vento a relva sopra

veios de areia sobre

o ruço das canções de fontana.

Um ouvido, apartado, escuta.

Um olho, segado,

dá sentido a tudo isso. ${ }^{28}$

\section{responsabilidade: para o outro}

As figuras da descontinuidade, do corte e da interrupção do outro, em Celan e Derrida, antecipam, aqui, a condição de relação em que se inscreve o modo particular com que Emmanuel Lévinas pensa a noção de responsabilidade.

Em geral, a questão da responsabilidade impõe-se como questão da resposta e, portanto, também como questão da voz e da escuta enquanto fundadoras de uma dimensão ética do dizer. Nesse sentido, a responsabilidade põe em questão também os limites e as possibilidades da voz e da escuta, bem como as consequências (para o eu e para o outro) do modo como 
entendemos e como lidamos, a cada relação, com esses limites e possibilidades.

"D'habitude, on est responsable de ce qu'on fait soimême", ${ }^{29}$ lembrará Lévinas, em entrevista concedida a Philippe Nemo e publicada em Étique et infini, em 1982. Marcando uma diferença em relação a seu próprio pensamento, o filósofo aponta, nessa passagem, para uma ideia mais corrente de responsabilidade, comumente associada a um eu que responde ora pelos próprios atos e ditos (e pelo implícito de suas consequências), ora pelos atos e ditos de um outro, quando então, ao aceitar tal responsabilidade, a voz do eu assume a resposta do outro, assina o outro como resposta.

Trata-se, nesse caso, de uma lógica da responsabilidade centrada na voz de um eu que presume a possibilidade (capacidade) de responder (dizer ou agir em resposta) por seus atos e ditos, via de regra, sem incorporar, ao seu cálculo do eu, aquilo pelo que o eu não é capaz de responder, aquilo que nele resiste e insiste enquanto porção estranha, desconhecida, inapreensível e não controlável de si. Em outras palavras, essa lógica da responsabilidade assume como pressuposto a possibilidade de conhecimento do eu (como uma totalidade), o que, por sua vez, presume a ideia de que o eu possa assumir a condição de objeto de si próprio.

Já do ponto de vista da ideia de uma responsabilidade que o eu assume pelo outro, trata-se igualmente de uma lógica da responsabilidade centrada num dito do eu que, ao assumir a resposta pelo outro (em lugar do outro), presume a possibilidade de dizer o outro em seu dito. Essa lógica da responsabilidade assume o pressuposto de que o outro, na condição de objeto do conhecimento do eu, possa ser apreendido em sua alteridade, ignorando-se que, no império dessa lógica transitiva, o outro não se nos apresenta, senão como uma redução à condição de um outro-eu, como diferença limitada ao que cabe ou não cabe nos domínios da relação com um eu.

Diante da sintaxe geral dessa responsabilidade mais corrente, talvez possamos pensá-la como uma espécie de responsabilidade transitiva, fundada no pressuposto da possibilidade (e da necessidade) de se circunscrever um eu ou um outro como objeto de um sujeito responsável, capaz de responder por um eu (objeto de si) ou por um outro (objeto do eu).

À diferença dessa compreensão transitiva e fortemente egótica - em que o outro não se configura senão como objeto do eu -, a noção de responsabilidade para Lévinas implica, desde o início, um corte com essa noção mais corrente e o imperativo de uma Atemwende. Sua noção de responsabilidade será, já de partida: “un pour autrui”. ${ }^{30}$

Desenvolvida pelo filósofo ao longo de sua obra ${ }^{31}$, a noção de responsabilité pour autrui, como já evidenciam as dife-
29. LÉVINAS, Emmanuel. Étique et infini, 1982, p.92.

30. Ibidem. Vide também: LÉVINAS, Emmanuel. Autrement qu'être, 1978, especialmente pp. 22-25.

31. Em especial: LÉVINAS, Emmanuel. Totalité et infini, 1971 e Autrement qu'être, 1978. 
32. BADIOU, Alain.

L'étique, 2003, pp. 41-54.

Ao mesmo tempo em que identifica no pensamento de Lévinas a matriz de uma reconfiguração da questão ética na contemporaneidade, o pensador francês flagra um "valor religioso" por trás do edifício reflexivo de Lévinas. Sua crítica, no entanto, funda-se centralmente numa compreensão do outro lévinassiano como diferença do eu, sem admitir uma dimensão de alteridade do outro para além desse eixo egótico - ponto que parece ser decisivo para a construção do estatuto de infinitude do outro em Lévinas. A diferença, em Lévinas, não se restringiria apenas a uma diferença em relação ao outro; a infinitude dessa diferença se impõe justamente por conta daquilo que o outro pode ser para além de uma lógica de relação com o eu. Nesse sentido, é importante considerar que também as consequências de uma ética lévinassiana, discutidas por Badiou, limitamse a essa sua circunscrição particular do outro lévinassiano.

33. DERRIDA, Jacques.

Violence e Methapysique, 1967, p.187-188.

34. LÉVINAS, Emmanuel.

Totalité et infini,1971, em especial o capítulo "Le visage et l'extériorité".

35. DERRIDA, Jacques.

Violence e Methapysique, 1967, p.165. rentes nuances de tradução para o português (responsabilidade para o outro, pelo outro, para outrem, para com o outro), desdobra-se, no esforço de seus inúmeros horizontes de escuta, em diferentes leituras nos mais diversos campos e vertentes do pensamento contemporâneo, distendendo-se desde a inscrição no contexto de uma moral cristã e de uma filosofia teológica (ou mesmo como um discurso da tolerância, ou da piedade, no sentido crítico da leitura de Alain Badiou ${ }^{32}$ ), passando por seus vieses como antropologia filosófica ou como modalidade de um humanismo existencialista, até seus desdobramentos como uma forma de fenomenologia do outro ou de uma ética da diferença.

No horizonte desta discussão, por força da limitação a um foco mais pontual de incisão no pensamento de Lévinas e da necessidade de se marcar o contraste com uma acepção mais corrente de responsabilidade, podemos pensar a noção lévinassiana como uma forma de responsabilidade intransitiva - ou, ao menos, podemos pensá-la no horizonte de uma in-transitividade da noção de responsabilidade, de uma resistência, de uma não-indiferença à transitividade da relação com o outro. Nesse sentido, essa noção assume como pressuposto justamente a impossibilidade de circunscrição do outro como objeto - a impossibilidade de totalização do outro, a impossibilidade de alcance do outro enquanto outro - e flagra, na violência da lógica que se mostra indiferente a tais impossibilidades, uma dinâmica egótica de relação, em que o outro é reduzido à condição de um alter-idem, à figura de uma identidade ex negativo, de um autre-Moi, ignorando-se sua condição de autre comme un Moi, ignorando-se sua diferença para além do axioma da relação com um eu. Vale lembrar, no entanto, que, em "Violence et Metaphysique”, Derrida se referirá a essa redução como sendo, a um só tempo, violenta e não violenta, na medida em que é também por conta da irredutibilidade da violência dessa relação transitiva e redutora do outro, que se impõe, como forma de resistência, uma abertura ao outro na relação. ${ }^{33}$

Para Lévinas, o outro, em sua alteridade, assume a forma de um outro absoluto, que, na condição de sua infinitude - de um outro que é infinitamente outro -, manifesta-se como uma exterioridade, a que o filósofo chama de visage, ${ }^{34}$ de rosto. Importante sublinhar aqui, no entanto, que essa exterioridade do outro, em Lévinas, não se desdobra a partir de uma lógica do interno-externo. Para Derrida, o pensamento de Lévinas rompe com um dimensionamento espacial da relação, ${ }^{35}$ ruptura de que seu ensaio Le temps et l'autre, de 1947, já dá testemunho concreto. A ideia lévinassiana de uma infinitude do outro (l'infiniment autre) não se apresenta, portanto, na forma de uma infinitude positiva, como no sentido clássico da infinitude de Deus ou de uma infinitude para além, fora da linguagem. A 
infinitude do outro, em Lévinas, dirá Derrida, impõe-se, antes, como uma negatividade da finitude, como in-finitude, in-défini e, justamente nesses termos, como resistência à totalização deliberada do outro numa redução finita, como resistência a uma dinâmica egótica da relação, indiferente à redução do outro à condição de um outro-eu. Ao invés de presumir o outro como mero objeto de si numa lógica indiferentemente transitiva da relação, para Lévinas, "la relation avec l'autre est une relation avec un Mystère". ${ }^{36}$

Todavia, esse mistério também não se apresenta como um enigma. O pensamento de Lévinas afasta-se justamente de uma ideia de que a relação seja uma espécie de jogo, em que ao eu caberia decifrar o outro em seus ditos e silêncios. Diante desse mistério do outro, do outro como mistério, Celan, em carta ao poeta francês René Char - que ele então traduzia -, dirá:

Àquilo que em sua obra não - ou ainda não - se abriu à minha compreensão, respondi com respeito e espera: não se pode ter a pretensão de compreender completamente isso seria desrespeito diante do desconhecido que habita o poeta ou que ainda o habitará. ${ }^{37}$

E também Derrida, a propósito da leitura de um poema de Celan, em Béliers, sinaliza sua não-indiferença para com o outro além da redução operada em toda relação: "La certitude d'une lecture assurée serait la première niaiserie ou la plus grave trahison". ${ }^{38}$

De todo o complexo pensamento lévinassiano, a partir do qual se organiza essa reformulação in-transitiva da noção de responsabilidade, três traços merecem breve destaque aqui, especialmente pelo que representam como esboço de um pensamento contemporâneo sobre a relação.

Primeiramente, é preciso lembrar que a noção de responsabilidade lévinassiana se constrói no contexto de um esforço de distanciamento do primado da ontologia, articulado na forma de uma inversão da tradicional ordem ontologia-ética, a partir da qual, para Lévinas, a ética passa a ter lugar como filosofia primeira. Se nos termos da tradição filosófica ocidental, a questão ética é de segunda ordem, como questão da relação entre duas instâncias já estabelecidas na ordem primeira da ontologia - a questão do ser antecederia, portanto, a questão do ser com -, uma das consequências diretas dessa inversão é a ideia de que é na relação - e somente a partir da relação, no primado da ordem ética - que um eu e um outro passam a se constituir como o eu e o outro da relação.

Portanto, vale destacar que, no contexto dessa inversão lévinassiana, a responsabilidade para o outro, como imperativo ético da relação, não se limita apenas a uma forma de respeito,
36. LÉVINAS, Emmanuel. Le temps et l'autre, 1983, p.63.

37. Dem, was sich meinem Verständnis in Ihrem Werk nicht - oder noch nicht öffnete, habe ich mit Respekt und Warten geantwortet: man kann nie den Anspruch erheben, vollständig zu begreifen -: das wäre Respektlosigkeit gegenüber dem Unbekannten, das im Dichter ist oder sein wird. KAUSSEN, Wolfgang. Ich verantworte Ich widerstehe Ich veweigere: Celans Shakespeare, 2001, p. 57.

38. DERRIDA, Jacques. Béliers Le dialogue ininterrompu, 2003, p.45. 
39. Essa posição manifesta-se, por exemplo, nos comentários que Lévinas faz à reflexão de Martin Buber sobre a relação eu-tu. Como diferença em relação ao trabalho desse pensador, Lévinas destaca justamente que, ao contrário de Buber, sua reflexão partiria da ideia do infinito para pensar a relação com o outro. LÉVINAS, Emmanuel., Totalité et infini, 1971, p.64-65. cuidado, solidariedade ou piedade para com um outro. Esse modo de relação com o outro tem também um papel fundante, é constitutivo do outro da relação. Daí seu caráter imperativo, como não-indiferença, como resistência à transitividade deliberada da relação, que se abre então à possibilidade de que o outro tenha lugar como um outro outro, comme l'infiniment autre, na irredutibilidade de sua alteridade.

É importante destacar, também, que a responsabilidade lévinassiana não representa apenas uma mudança de foco ou de objeto do sujeito responsável - do eu para o outro. Essa reformulação se constrói no mesmo movimento de uma desconstrução de certa idealização do face a face ${ }^{39}$, que pressuporia a possibilidade ideal do encontro, do alcance do outro, da reciprocidade e da simetria na relação eu-outro. É, portanto, contra um pensamento idealizado da relação - e, em especial, contra suas consequências trágicas para o outro- que Lévinas assume a infinitude, a descontinuidade e a irredutibilidade do outro como condições fundamentais de toda relação. É contra o pressuposto da relação como um continuum do eu no outro que se impõe, para Lévinas, uma descontinuidade do outro, uma Atemwende, um corte capaz de abrir a relação para os assombros e as surpresas da alteridade absoluta do outro.

E vale destacar, ainda, que a noção de responsabilidade para o outro não significa uma simples transferência de responsabilidade, tampouco uma reformulação dos deveres assumidos pela voz responsável. Ao provocar o deslocamento de uma transitividade corrente para o horizonte in-transitivo de sua noção de responsabilidade, Lévinas promove o deslocamento de uma responsabilidade centrada na voz (no eu que diz o outro) para uma responsabilidade centrada na escuta (no eu atento ao outro, no outro que se impõe como atenção do eu), provocando, na ordem e na dinâmica da relação, um descentramento do eu - a quem caberá ouvir antes de dizer, dizer a partir da escuta - e uma abertura ao outro - a um outro que não surge mais como mero objeto do dito, mas como o horizonte de uma atenção.

\section{ouvir, escutar}

A escuta do ouvido apartado, no verso de Celan, reverbera, aqui, na possibilidade de leitura do pour autrui lévinassiano como uma forma de atenção. E, a esse propósito, um comentário pontual de Heidegger, em sua conferência sobre "Hölderlin e a essência da poesia" [Hölderlin und das Wesen 
der Dichtung], de 1937, faz aqui as vezes de anacruse de uma discussão em torno da atenção da escuta: "Saber ouvir não é apenas a consequência de falar um com o outro, ao contrário, é sua condição". ${ }^{40}$

Sublinhe-se que Heidegger não se refere apenas a um ouvir (Hören), mas a um saber ouvir (Hörenkönnen), ou seja, a um modo particular de dar ouvidos, a um ouvir que é não é condição passiva, a um ouvir que não se limita à percepção física de um sentido. Saber ouvir é uma habilidade, é da ordem de um saber fazer.

Assim, se a noção mais corrente de responsabilidade assume comumente um caráter ativo - em geral, da voz como resposta -, isso não significa que o deslocamento lévinassiano na direção de uma responsabilidade para o outro - da atenção, da escuta como resposta - implique um caráter passivo dessa forma de responsabilidade. Atentar ao outro não é apenas aceitar, aceder, receber; a atenção ao outro é uma atividade. É preciso saber atentar ao outro, é preciso construir essa atenção, essa abertura. Nesse sentido, com todas as reservas de uma transição tão imediata entre pontos do pensamento de Heidegger e Lévinas, ${ }^{41}$ o comentário heideggeriano parece tocar em uma questão que é também importante na discussão desse pour autrui lévinassiano, entendido, a partir dessa perspectiva, como uma forma ativa de atenção e de escuta que funda a noção de responsabilidade para o outro.

Mas escutar não é simplesmente ouvir, como podemos ler no ensaio À l'écoute, ${ }^{42}$ de Jean-Luc Nancy. O filósofo toma como ponto de partida uma distinção entre o visual e o sonoro, lembrando que a noção de fenômeno é da ordem da manifestação, da aparência, e que, portanto, pode-se dizer que grandes questões da filosofia, de Kant a Heidegger, estariam muito marcadas pelo campo do visual. Ocorre que, enquanto o visual é algo que aparece e desaparece como imagem, algo (mimético) que "persists until its disappearance", o sonoro é algo que surge e some como ressonância, algo (metético) que "appears and fades away into its permanence". ${ }^{43}$ No caso do visual, a imagem (a forma, a ideia) é algo que se nos apresenta, nos vemos diante dela, nós a vemos em seu diante de nós; já no caso do sonoro, a ressonância (o tom, o timbre) pressupõe alguma forma de repercussão, um vibrar junto, uma participação (methexis). Como metáfora da construção de sentido, o sonoro evidenciaria, portanto, uma relação que não pode ser centrada apenas numa das partes, uma relação que só faz sentido enquanto repercussão, reverberação. Nesses termos, ouvir o outro presumiria, já de partida, uma outra forma de relação, marcada por uma abertura à interferência, à reverberação do outro em mim.
40. Das Hörenkönnen ist nicht erst die Folge des Miteinandersprechens, sondern eher umgekehrt die Voraussetzung dafür. HEIDEGGER, Martin. Hölderlin und das Wesen der Dichtung, 1981, p. 39.

41. Vale lembrar que o afastamento do pensamento de Lévinas de uma ontologia - de que a noção de responsabilidade para o outro é uma consequência - é também, em grande medida, um afastamento de Heidegger e do pensamento Heideggeriano.

42. NANCY, Jean-Luc. $\dot{A}$ l'écoute, 2002. Por uma questão meramente circunstancial, as referências, aqui, serão feitas a partir da tradução para o inglês: NANCY, Jean-Luc. Listening, 2007.

43. NANCY, Jean-Luc. Listening, 2007, p.2. 
44. Ibidem, p.5.

45. Ibidem, p.9.
A partir dessa diferenciação inicial, Nancy pontua então uma distinção entre o ouvir (entendre, to hear) e o escutar (écouter, to listen). Enquanto ouvir é sobretudo perceber algo pelo sentido da audição, mas sem necessariamente dar atenção a esse algo ouvido, escutar é sempre um gesto atento, é dar atenção a esse algo como algo, é esforçar-se para ouvir, é procurar ouvir: "To listen ist tendre l'oreille - literally, to strech the ear [...] it is an intensification [do ouvir] and a concern, a curiosity or an anxiety. ${ }^{44}$ Diferentemente da distração do ouvir, que tudo percebe indiferentemente, a escuta é portanto um esforço, um gesto, uma atenção, um cuidado. Poderíamos mesmo falar de um trabalho de escuta. E é nesse modo de ouvir que Nancy reconhece um modelo para se repensar o sentido da relação - como repercussão de um eu num outro:

When one is listening, one is on the lookout for a subject, something (itself) that identifies itself by resonating from self to self, in itself and for itself, hence outside of itself, at once the same-as and other-as itself, one in the echo of the other, and this echo is like the very sound of its sense. ${ }^{45}$

Se a partir de Heidegger podemos destacar o caráter ativo do pour autrui como forma particular de relação com o outro, as distinções de Nancy reforçam a leitura da responsabilidade lévinassiana como uma forma particular de atenção ao outro, como uma responsabilidade da escuta. Diante do imperativo da não-indiferença, impõe-se portanto um trabalho de escuta.

\section{a orelha que assina}

Podemos dizer, com Lévinas, que a noção mais corrente de responsabilidade - como uma responsabilidade da voz - é pouco marcada pela escuta do outro (uma responsabilidade mouca, se não surda). Mas não podemos deixar de observar também que a responsabilidade para o outro - como uma responsabilidade da escuta - não é uma responsabilidade sem voz (uma responsabilidade rouca, nem mesmo muda).

Ainda que como resistência, como não-indiferença à transitividade da relação com o outro, a responsabilidade Lévinassiana também se inscreve na ordem de uma resposta, também tem uma voz que necessariamente reduz o outro como um outro da relação, como um valor de outro na dinâmica de relação - não se trata, afinal, de presumir a substituição da transitividade por uma condição idealizada de intransitividade da relação. Porém, à diferença do que ocorre na modalidade mais corrente 
de responsabilidade, a resposta lévinassiana não é indiferente à sua condição de redução, tampouco à in-finitude do outro. E é na medida exata dessa não-indiferença - dessa atenção, dessa escuta - que o outro repercute no eu como alteridade irredutível e que o eu, sob a ação desse impacto, diz o outro.

Nesses termos, podemos dizer que o trabalho de escuta, fundado numa interrupção da continuidade do eu no outro numa Atemwende -, também configura o outro.

Em Otobiographies, ${ }^{46}$ Derrida se vale da figura da orelha do outro (l'oreille de l'autre) para, ao longo de uma reflexão sobre a obra de Nietzsche, desenvolver uma discussão sobre questões como biografia (autobiografia), assinatura e nome próprio.Nesse contexto, Derrida trabalha com a ideia de que aquilo a que nos referimos - que assinamos - como Nietzsche e sua obra seria uma construção posterior ao momento em que Nietzsche associa seu nome a seu texto. Para Derrida:

[...] the signature becomes effective - performed and performing - not at the moment it apparently takes places, but only later, when ears will have managed to receive the message. In some way the signature will take place on the addressee's side, that is, on the side of him or her whose ear will be keen enough to hear my name, for example, or to understand my signature, that with which I sign. [...] Nietzsche's signature does not take place when he writes. [...] In other words, to abbreviate my remarks on a very lapidary fashion, it is the ear of the other that signs. ${ }^{47}$

A orelha do outro, não qualquer orelha, mas uma orelha atenta, uma orelha que é também um ouvido à escuta, aquela que for "keen enough to hear my name", essa orelha seria a responsável por assinar o outro, por fazer valer o outro como um nome - o nome que a orelha assina em sua escuta. Para Derrida, esta também seria a lógica dos textos e das obras em geral: "Every text answers to this structure. It is the structure of textuality in general. A text is signed only much later by the other" ${ }^{48}$

Com Derrida, portanto, o trabalho de escuta evidenciase também como um trabalho de assinatura. Em meu gesto de escuta, circunscrevo o outro como um nome que passa a valer o outro.

A partir disso, podemos pensar que a responsabilidade para o outro se impõe duplamente:há uma responsabilidade pelo que uma atenção e uma não-indiferença ao outro é capaz de representar como resistência à sua redução deliberada a um outro-eu; mas há também uma responsabilidade pelo que essa escuta atenta do outro acaba assinando comoum outro: "Politically and historically [...] it is we who have been entrusted with the responsability of the signature of the other's text which we have inherited" ${ }^{49}$
46. DERRIDA, Jacques.

Otobiographies, 1984. Em sua edição canadense, que tomo aqui por referência, são incorporadas ao conjunto as discussões de três mesas redondas realizadas em 1979, na Universidade de Montreal: DERRIDA, Jacques. The ear of the other, 1985.

47.DERRIDA, Jacques. The ear of the other, 1985, pp. 50-51

(grifo meu).

48. Ibidem, p.51.

49. Ibidem. 
50.A esse respeito, vale conferir o trabalhoque vem sendo desenvolvido por Maria Clara Castellões de Oliveira no campo das relações entre ética e tradução, com destaque para sua discussão do pensamento de autores como Derrida e Lévinas no horizonte de uma reflexão sobre questões éticas da tradução na contemporaneidade. Especialmente: OLIVEIRA, Maria Clara Castellões de. A contribuição de filósofos judaicos para a ética do traduzir na contemporaneidade, 2012 e A tradução e a ética do para o outro, 2013.

51. DERRIDA, Jacques. Violence e Methapysique, 1967, p.164.

\section{tradução, leitura, crítica: al fine}

Em geral os discursos mais correntes sobre o estatuto da tradução já se articulam, de partida, em torno do eixo de um dever, de um dever dizer, de um dever fazer ou, para dizer o mesmo nos idiomas da especificidade tradutológica: de um dever de transposição, de passagem, de transformação, conforme as afinidades eletivas de cada um. Afinal, abstraindo-se de sua condição tradutória, os fazeres da tradução, em sua condição de prática discursiva, são sempre também fazeres de outra ordem, da ordem das especialidades técnicas, da criação literária, da crítica - a tradução é sempre tradução de uma determinada prática discursiva. E é justamente na medida em que esses fazeres se envelopam na forma de um certo dever, que a tradução, enquanto tradução de algo, tem lugar. É quase como se pudéssemos dizer que, no mesmo gesto em que se articula como uma prática - um fazer -, a tradução surge sempre já como um dever e, portanto, como uma forma de responsabilidade.

A responsabilidade lévinassiana, pensada a partir das diferentes reverberações aqui destacadas, coloca-nos diante da tarefa de repensar esses deveres da tradução ${ }^{50}$ para além de um centramento no dito, o que, por sua vez, significa também pensar esses deveres a partir da condição de infinitude e descontinuidade do outro e sob o signo duplo de uma responsabilidade de escuta e de assinatura do outro.

Todavia, cabe aqui lembrar, com Derrida, que a ética e a responsabilidade lévinassianas não se limitam à ordem dos deveres: "n'oublions pas que Lévinas ne veut pas nous proposer des lois ou des règles morales, il ne veut pas déterminer une morale mais l'essence du rapport éthique en général [...] il s'agit d'une Étique de l'Étique" ${ }^{51}$. Nessa perspectiva, repensar os deveres da tradução - e a tradução como um dever - implica menos uma reformulação desses deveres do que uma reorientação do campo de responsabilidades da poiesis tradutória - menos outro afora do que costa dentro.

Diante da condição de descontinuidade do outro, a relação tradutória não pode ser entendida simplesmente como via de acesso. Nem como via, nem como acesso. Antes, a tradução é a ocasião de um esforço relacional, é o acontecer de uma poiesis da relação com o outro, que, como tal, é sempre, em alguma medida, transformadora do outro e do eu: do outro apartado, recortado, transformado, assinado; e do eu, que ao apartar, recortar, transformar e assinar o outro, opera, também, em si e para si, uma transformação de seus valores. Tradução é trabalho de relação. Daí ser preciso, lévinassianamente, repensar o eu para pensar o outro da tradução. Um discurso de defe- 
sa do outro que não assuma a possibilidade de transformação de si mesmo não faz muito mais do que perpetuar uma ordem relacional transitiva e egótica, fundada numa ética da diferença que limita a diferença ao axioma do eu e que não dá ocasião para que reverberem, na relação, as surpresas e os assombros de um outro para além do espelho.

Diante da condição de infinitude do outro, não há como se pensar tradução senão como recorte. Todo recorte passa a valer o outro. Cabe ao tradutor, então, reconhecer a condição em que opera seus cortes. Traduzir o outro, ao invés de um compromisso mimético com a totalidade e com a fidedignidade - horizonte muito distante da condição real em que a tradução (e qualquer outra prática discursiva) tem lugar enquanto prática de relação com o outro -, reorienta-se, portanto, como um compromisso metético com a atenção ao recorte que assina o outro.

Por sua vez, para apontar aqui na direção de uma responsabilidade da leitura, ler o outro em tradução, ao invés de um movimento marcado exclusivamente pela expectativa do encontro com um outro-eu - nossa projeção particular do outro como único horizonte de leitura, dissimulada em nome de uma fidedignidade ao outro, que, não raro, apresenta-se como argumento de autoridade -, reorienta-se, assim, como uma ética da não-indiferença na leitura do outro em tradução: não-indiferença à nossa própria tendência de reduzir o outro a uma continuidade de nós mesmos; não-indiferença à condição de recorte e assinatura de toda leitura; não-indiferença ao trabalho de escuta que funda toda tradução.

Já quanto à crítica de tradução, ao invés de se pensar essa atividade exclusivamente a partir do tradicional eixo de continuidade do outro - movimento que, em geral, reduz a crítica a uma forma de reconhecimento de si própria, na medida em que não é capaz de acomodar em seu horizonte de expectativa senão aquilo que satisfaz uma imagem já preconcebida do outro-, caberia reorientá-la na direção do horizonte que se abre com a possibilidade de admitir um outro que, descontinuado de mim, me descontinua.

Entre a certeza da factualidade da existência do outro e as dúvidas de seus por detrás, a responsabilidade para o outro se impõe como o próprio gesto da relação tradutória, sempre aquém de todo ouvidos, mas quiçá para além de ouvidos moucos, no horizonte de uma Atemwende. Um gesto imperativo de corte no horizonte de uma escuta com menos indiferença. Um gesto que assina o outro como nome do outro na relação. Um gesto que transforma o outro para mantê-lo como força de ressignificação de nós mesmos - para manter o outro em epígrafe. 


\section{Referências}

BADIOU, Alain. L'étique: essai sur la conscience du mal. Caen: Nous, 2003.

BERMAN, Antoine. L'épreuve de l'étranger. culture et traduction dans l'Allemagne romantique: Herder, Goethe, Schlegel, Novalis, Humboldt, Schleiermacher, Hölderlin. Paris: Gallimard, 1984. [Existe versão em português: ]

CARDOZO, Mauricio Mendonça. Tradução, apropriação e o desafio ético da relação. In: Oliveira, Maria Clara Castellões de; Lage, Verônica Lucy Coutinho (Org.). Literatura, crítica, cultura I. 1. ed. Juiz de Fora: Editora UFJF, 2008. v. I, p. 179190.

CELAN, Paul. Der Meridian. Endfassung, Entwürfe, Materialien, organizado por Bernhard Böschenstein e Heino Schmull. Frankfurt, Suhrkamp, 1999.

Die Gedichte: Kommentierte Gesammtausgabe in einem Band. Organização e comentários de Barbara Wiedemann. Frankfurt: Suhrkamp, 2003.

.Renverse du souffle. Tradução e notas de Jean-Pierre Lefebvre. Paris: Seuil, 2003.

O Meridiano. Tradução de Flávio Kothe. Guará, Goiânia, v. 1, n. 1, p. 47-57, jul./dez. 2011.

DERRIDA, Jacques. Violence et métaphysique: essai sur la pensée d'Emmanuel Lévinas. In: L'écriture et la différance. Paris: Seuil, 1967, p.117-228.

. Otobiographies:l'enseignement de Nietzsche et la politique du nom propre. Paris: Galilée, 1984

The ear of the other. Otobiography, Transference, Translation. Tradução de Avital Ronell, organização de Christie V. McDonald. Nova Iorque: Schocken Books, 1985, p.1-38.

. Schiboleth pour Paul Celan. Paris: Galilée, 1986.

. Béliers - Le dialogue ininterrompu: entre deux infinis, le poème. Paris : Galilée, 2003.

FROTA, Maria Paula. A singularidade na escrita tradutora: linguagem e subjetividade nos estudos da tradução, na linguística e na psicanálise. São Paulo e Campinas: FAPESP e Pontes, 2000. 
GADAMER, Hans-Georg. Wer bin Ich und wer bist

Du.Frankfurt: Suhrkamp, 1986.

. Quem sou eu, quem és tu? Tradução de Raquel Abi-

Sâmara. Rio de Janeiro: EdUERJ, 2005.

GUIMARÃES ROSA, João. Grande Sertão: Veredas. 27. ed.

Rio de Janeiro: Nova Fronteira, 1986.

HEIDEGGER, Martin. Hölderlin und das Wesen der

Dichtung. In: Heidegger, Martin. Erläuterungen zu

Hölderlins Dichtung. Frankfurt: Vittorio Klostermann, 1981, p. 33-48.

KAUSSEN, Wolfgang. Ich verantworte Ich widerstehe Ich veweigere: Celans Shakespeare, posfácio. In: SHAKESPEARE, William. Einundzwanzig Sonette. Tradução de Paul Celan, 2001.

Frankfurt, Leipzig: Insel, 2001, p. 49-90.

LÉVINAS, Emmanuel. Totalité et infini. Paris : Martinus Nijhoff, 1971.

. Autrement qu'être. Paris: Martinus Nijhoff, 1978. Étique et infini. Paris: Librairie Arthème Fayard et

Radio France, 1982.

1983.

. Le temps et l'autre, 9. ed. Paris: Quadrige-Puf, . Alterité et transcendence. Paris: Fata Morgana, 1995.

NANCY, Jean-Luc. À l'écoute. Paris: Galilée, 2002.

Listening. Tradução de Charlotte Mandell. Nova

Iorque: Fordham University Press, 2007.

OLIVEIRA, Maria Clara Castellões de. A tradução e a ética do para o outro: E agora, aonde vamos?. In: Veras, Viviane; Esteves, Lenita (org.). Vozes da tradução, éticas do traduzir. São Paulo: Humanitas, 2013. (no prelo)

A contribuição de filósofos judaicos para a ética do traduzir na contemporaneidade. Revista Letras, Curitiba, n. 85, p. 151-161, 2012.

PÉRET, Benjamin. Euvres complètes, vol.1. Paris:

Association des amis de Benjamin Péret; Éric Losfeld, 1969.

RODRIGUES, Cristina Carneiro. A ética da apropriação.

Tradução \& Comunicação. Revista Brasileira de Tradutores, São Paulo, n. 17, p.21-28, 2008. 
ROUSSEAU, Jean-Jacques. Emile ou De l'éducation. Paris: Pourrat Frères, 1841.

SCHLEIERMACHER, Friedrich. Sobre os diferentes métodos de tradução. Tradução de Margarete von Mühen Poll. In: HEIDERMANN, Werner, org. Clássicos da teoria da tradução. Florianópolis: UFSC, Núcleo de Tradução, 2001, p. 26-87.

STROPARO, S.M. O caminho do silêncio: Mallarmé e Blanchot. Letras de Hoje, Porto Alegre, v. 48, n. 2, p. 191-198, abr./jun. 2013

VENUTI, Lawrence. The translator's invisibility: a history of translation. Londres e Nova Iorque: Routledge, 1995. 